\title{
Psicologia Jurídica: Notas sobre um Novo Lobo Mau da Psicologia
}

\author{
Lisandra Espíndula Moreira ${ }^{1}$ \\ 1Universidade Federal de Minas Gerais, MG, Brasil.
}

\author{
Laura Cristina Eiras Coelho Soares ${ }^{2}$ \\ 2Universidade Federal de Minas Gerais, MG, Brasil.
}

Resumo: Nesse artigo objetivamos analisar o debate sobre direito(s) e questões jurídicas em territórios acadêmicos, profissionais e formativos, a partir do questionamento se seria a Psicologia Jurídica o novo lobo mau da Psicologia. Em territórios acadêmicos, na perspectiva teórica da Psicologia Social há estudos importantes que enfrentam a interface com o campo dos direitos e do judiciário, em especial, o debate sobre a judicialização da vida. Nos territórios de atuação profissional, o cenário de judicialização da vida tem provocado aumento das demandas sociais ao Judiciário que responde criando cargos para psicólogos ou acionando profissionais que já se encontram na rede pública, porém laborando em outras políticas públicas, tais como saúde e assistência social. O crescimento de processos éticos contra profissionais no Sistema Conselhos reflete o despreparo para lidar com demandas de elaboração de documentos que são remetidos ao Sistema de Justiça. Entretanto, nos territórios de formação, geralmente, a Psicologia Jurídica não aparece como disciplina obrigatória. $\mathrm{O}$ aspecto facultativo da inclusão desse conteúdo na formação discente possui impactos diretos na atuação do psicólogo e na construção de políticas científicas na área. Aproveitando o momento de discussão da formação de psicólogo no Brasil, buscamos problematizar as transformações no campo da Psicologia, em especial, a ampliação da judicialização das vidas. Nesse sentido, é necessário posicionar a Psicologia Social Jurídica como um importante referencial crítico a ser colocado nesse debate, como estratégia de posicionamento engajado na garantia dos direitos humanos, considerando as questões éticas, políticas, sociais e históricas que envolvem a(s) subjetividade(s) nesse contexto.

Palavras-chave: Psicologia Jurídica, Judicialização, Formação, Pesquisa científica, Atuação do psicólogo. 


\title{
Juridical Psychology: Notes on a New Big Bad Wolf Stereotype
}

\begin{abstract}
In this article, we aim to analyze the debate on legal right (s) and juridical issues in academic, professional and formative assessments, and to evaluate if Juridical Psychology fits the Big Bad Wolf stereotype. In academic assessments, there are important studies in the theoretical perspective of Social Psychology that illustrate the interface with the field of rights and the judiciary, in particular, the debate on the judicialization of life. In the territories of professional activity, the judicialization of life has provoked an increase in social demands to the judiciary, which responds by creating positions for psychologists or by activating professionals already in the public network, but working in other public policies such as health and social assistance. The growth of ethical processes against professionals in the Councils System reflects the unpreparedness to deal with the demands of elaboration of documents that are sent to the Justice System. However, in the formative territories, generally, Juridical Psychology does not appear as a compulsory subject matter. The optional aspect of the inclusion of this content in the student formation has direct impacts on the psychologist's performance and the construction of scientific policies in the area. Taking advantage of the moment of discussion of the formation of psychologists in Brazil, we seek to problematize the transformations in the field of Psychology, in particular, the extension of the judicialization of lives. In this sense, it is necessary to position Social Juridical Psychology as an important critical reference to be placed in this debate, as a positioning strategy engaged in guaranteeing human rights, considering the ethical, political, social and historical issues that involve subjectivity (s) in this context.
\end{abstract}

Keywords: Juridical Psychology, Judicialization, Formation, Scientific research, Psychologist performance.

\section{Psicología Jurídica: Notas sobre el Nuevo Lobo Malo de la Psicología}

Resumen: En este artículo pretendemos analizar el debate sobre derecho(s) y cuestiones jurídicas en territorios académicos, profesionales y formativos, a partir del cuestionamiento si sería la Psicología Jurídica el nuevo lobo malo de la Psicología. En los territorios académicos, en la perspectiva teórica de la Psicología Social hay estudios importantes que enfrentan la interfaz con el campo de los derechos y el poder judicial, en especial, el debate sobre la judicialización de la vida. En los territorios de la práctica profesional, el escenario de judicialización de la vida ha provocado aumento de las demandas sociales al Poder Judicial que responde creando cargos para psicólogos o accionando profesionales que ya se encuentran en la red pública, pero trabajando en otras políticas públicas, tales como salud y asistencia social. El crecimiento de procesos éticos contra profesionales en el Sistema Consejos refleja la falta de preparación para hacer frente a las demandas de elaboración de documentos que son remitidos al Sistema de Justicia. Sin embargo, en los territorios de formación, generalmente, la Psicología Jurídica no aparece como disciplina obligatoria. El aspecto facultativo de la inclusión de ese contenido en la formación discente tiene impactos directos en la actuación del psicólogo y en la construcción de políticas científicas en el área. Aprovechando el momento de discusión de la formación de psicólogo en Brasil, buscamos problematizar las transformaciones en el campo de la Psicología, en especial, la ampliación de la judicialización de las vidas. En este sentido, es necesario posicionar a la Psicología Social Jurídica como un importante referencial crítico a ser colocado en ese debate, como estrategia de posicionamiento comprometido en la garantía de los derechos humanos, considerando las cuestiones éticas, políticas, sociales e históricas que involucran la(s) subjetividad(s) en este contexto.

Palabras clave: Psicología Jurídica, Judicialización, Formación, Investigación científica, Desempeño del psicólogo. 


\section{Introdução - Quem tem medo do lobo mau?}

Ao refletirmos sobre as inexistências que são produzidas no território acadêmico, nas políticas de pesquisa, de formação e nos campos de atuação, a partir da nossa inserção como docentes e pesquisadoras da Psicologia na interface com o Direito, buscamos nesse artigo compreender o descompasso na ocupação da Psicologia jurídica em territórios de pesquisa, de atuação e de formação, mapeando esses territórios a partir da dúvida se seria a psicologia jurídica o novo "lobo mau" da psicologia. Em especial, analisaremos as invisibilidades da Psicologia Jurídica nos debates da Psicologia Social e, a outra face dessa moeda, a invisibilidade da Psicologia Social nos espaços de debate da Psicologia jurídica. A partir desse objetivo vislumbramos um recorte, afastado de qualquer neutralidade, posto que reflete as inquietações na condição de docentes dessa área ora invisibilizada por um olhar de não identificação com o campo, ora fagocitada por outros campos que preferem optar por outras nomeações: a Psicologia Jurídica.

Como qualquer fronteira, o espaço de conexão entre Direito e Psicologia se caracteriza por disputas na definição de territórios. Não é novidade que esses conflitos produzem mal-estar na atuação dos profissionais da Psicologia no Sistema de Justiça, como bem analisou Arantes (2008). Entretanto, interessa-nos aqui analisar como essa disputa marca a produção de conhecimento e a atuação profissional dentro do campo da Psicologia.

Cabe pensar que, no acirramento de debates sobre modelos de ciência, com algumas posições que visam desqualificar perspectivas epistemológicas não positivistas, a reflexão aqui proposta dialoga de maneira ampliada com o campo das ciências humanas e da Psicologia como um todo. Entretanto, tomar a Psicologia Jurídica como referência para análise possibilita delimitar movimentos de captura do humano nesses mecanismos específicos dos códigos jurídicos que nos convocam enquanto docentes, profissionais e estudantes da subjetividade.

Ao revisitarmos o clássico texto de Codo (1984), que analisa a articulação da Psicologia com as questões organizacionais e do trabalho, questionamos se seria a Psicologia Jurídica o novo "lobo mau" da Psicologia. Porque quando falamos Psicologia Jurídica, os psicólogos sociais críticos, por vezes, não querem se associar a esse termo? O que esse termo carrega, que parece remeter ao modo como a área de conhecimento foi construída historicamente como ferramenta de normatização, vigilância e controle (Brito, 1993).

Codo (1984) reivindica a importância da inserção dos psicólogos nas organizações ${ }^{1}$ para que seja possível realizar uma atividade de transformação a partir de um movimento interno. Aos olhares críticos direcionados ao trabalhador alocado nas organizações, o autor responde que estes culminam por poupar "[...] os industriais do incômodo de ter entre suas fileiras um profissional preocupado com a defesa dos direitos do trabalhador" (p. 197).

Em entrevista ao Jornal do CRP/SP, Codo (1996) analisa a intenção do seu texto que teve grande repercussão, que buscava compreender porque a Psicologia não levava em conta o trabalho como uma categoria. Essa desconsideração se desdobrava numa desconexão entre a produção de conhecimento e a atuação dos profissionais: "havia psicólogos que atuavam sem nenhum embasamento crítico e psicólogos que faziam a crítica sem nenhum embasamento prático. O 'lobo mau' trata a questão da possibilidade do exercício da crítica dentro da ação profissional" (Codo, 1996).

Aproveitando essa aproximação, observamos curiosamente um descompasso semelhante em relação à Psicologia Jurídica, principalmente no diálogo com a Psicologia Social. Em movimentos de retração e ampliação, esse campo apresenta muitas produções no território acadêmico, especialmente na análise da judicialização da vida, como crítica das práticas jurídicas. Entretanto, essa produção não se consolida, por exemplo, como disciplina obrigatória na formação.

Enquanto campo de atuação, por conta dos movimentos de judicialização, há cada vez mais a abertura de postos de trabalho para psicólogos na interface com o Direito, mas que em alguns desses espaços tem sua atuação crítica limitada, centrando a prática em atuações periciais e na produção de documentos. Equivale a dizer que parecem posicionados como grupos distanciados de um lado psicólogxs jurídicxs

\footnotetext{
${ }^{1}$ No texto, em função da época na qual foi escrito, utiliza originalmente o termo “indústria” (p. 197). Para fins de atualização do presente artigo optou-se por substituir por organizações.
} 
como técnicos/peritos e de outro psicólogxs sociais como teóricos críticos.

Esse tensionamento entre práticas positivistas e perspectivas mais críticas, presente em diversas áreas da Psicologia, encontra na Psicologia Jurídica um território de demandas voltadas especificamente para abordagens de respostas rápidas ao Direito tornando-se um território importante de análise. Esse embate tem desdobramentos epistemológicos que nos convocam a reafirmar o compromisso da Psicologia com os direitos humanos e a necessidade de pensar as vidas infames ${ }^{2}$ no confronto com as instâncias de poder.

A partir desse descompasso, outros questionamentos surgem. Qual é a Psicologia jurídica queremos? Como fomentar uma perspectiva crítica em atuações da Psicologia Jurídica? Com qual Psicologia Social a Psicologia Jurídica quer dialogar? Com quais aproximações teóricas podemos/desejamos construir uma Psicologia Social Jurídica?

Nessa discussão, cabe atentar para algumas pistas que o debate sobre judicialização da vida nos apresenta. Compreende-se judicialização a partir da definição apresentada por Rifiotis (2012) que sinaliza um duplo movimento: "[...] amplia o acesso ao sistema judiciário e ao mesmo tempo desvaloriza outras formas de resolução de conflito, reforçando ainda mais a centralidade do judiciário" (p. 19). Aguiar, Fonseca e Daros (2018) contextualizam que:

O que temos como expressão máxima da nova ordem mundial é a expansão da função judiciária no corpo social, em seu duplo movimento de invasão (capilarização) no ínfimo da vida e de condensação (tomada para si) das funções de diferentes instituições - processamentos permanentes entre planos, micro e macropolíticos, em uma ordem sustentada pelo controle (p. 80).

Nessa centralidade do judiciário, é possível identificar uma lógica colonizadora de buscar justiça, que nos convocaria, contrapondo essa lógica pela ocupação e pela resistência, a pensar em habitar as encru- zilhadas. Nascimento e Scheinvar (2012) salientam a importância das análises foucaultianas para a compreensão da judicialização da vida enquanto lógica de julgamento e punição, não apenas para denunciar a produção de desigualdades, mas para pensar formas de superação.

Ao pensar a judicialização no cenário brasileiro, como uma bio/necropolítica, faz-se necessário pensar o modo como os diferentes sujeitos estão marcados em relação às instâncias jurídicas, em especial, quando entram em cena diferenças raciais ${ }^{3}$, de gênero, sexualidade, classe, entre outras. As políticas descritas por Foucault como produção de modos de viver camuflam a produção de formas de morrer (Uziel, Scisleski, Barros, \& Bicalho, 2018, p. 4), sendo imperativo questionar como a Psicologia se posiciona e quais são nossas ferramentas para retomar construções coletivas e inventivas.

Dentre os riscos da judicialização, que se tornam um problema para a Psicologia Social, Aguiar et al. (2018) sinalizam que estão os processos de individuação, visto que os direitos sociais se tornam cada vez mais obsoletos. Esses processos afetam diretamente as subjetividades, ao culpabilizar, criminalizar e punir aquelas que não correspondem a alguma norma. Nesses processos, enquanto profissionais, há uma demanda insistente para nos capturar em práticas de vigilância e controle. Além disso, nas articulações com as instâncias jurídicas, a Psicologia é instigada a produzir ferramentas cada vez mais céleres: "As encomendas realizadas ao Poder Judiciário crescem exponencialmente, nas últimas décadas, gerando uma inflação jurídica sem proporção, a qual, o próprio Judiciário não consegue administrar" (Lemos, 2018, p. 145). Não há tempo nem espaço nos documentos elaborados, a partir dessa demanda, para análises complexas e demoradas.

Equivale a dizer que a instituição justiça produziu outra forma de habitar e viver a experiência do sujeito na atualidade (Brito, 2012). A subjetividade judicializada é abordada na medida em que se considera a experiência subjetiva inserida na trama do judiciário no contexto de judicialização da vida e do cotidiano.

\footnotetext{
${ }^{2}$ Esse embate aparece na análise de Foucault (2006) sobre a vida dos homens infames: "Vidas que são como se não tivessem existido, vidas que não sobrevivem senão do choque com um poder que mais não quis que aniquilá-las, ou pelo menos apagá-las” (p. 210).

${ }^{3}$ Como aborda Lima (2018), aproximando as leituras de Foucault e Mbembe, é necessária uma virada analítica da sociedade brasileira a partir do violento processo da escravidão, desmantelando "o mito da democracia racial e a ideia da cordialidade como elementos modeladores das relações sociorraciais no Brasil” (Lima, 2018, p. 29).
} 
Nesse movimento, a noção de verdade ganha novas formas, reivindicando a herança da Psicologia do testemunho em novas configurações como delação premiada e depoimento especial ${ }^{4}$.

A noção de direito também se reconfigura, confundindo-se com vantagem, ganho e privilégio. Além disso, apesar do intenso enfoque no judiciário, o endereçamento transpassa a reivindicação para "todo um campo de disputas, de litígios que se instala nas relações de vizinhança - entre grupos, indivíduos, instituições, entre movimentos sociais, entre nós trabalhadoras sociais" (Aguiar et al., 2018, p. 80).

A judicialização invade os territórios mais amplos das relações sociais, oferecendo modos padronizados e burocratizados de resolução de conflitos. Não se restringe aos tribunais, ou melhor, expande essa lógica com réplicas e franquias a serem implantadas em escolas, empresas, associações, movimentos, famílias, dentre outros. Cada vez mais questões jurídicas são citadas nas relações cotidianas, tais como nomes de leis (Maria da Penha, feminicídio, ficha limpa, bullying, Estatuto da Criança e do Adolescente), artigos e direitos, tendo como debates como garantir, como judicializar, como negociar. Temas que mesmo as atuações da Psicologia mais distantes da área jurídica já devem ter percebido e sido afetadas.

Para levar adiante essas reflexões, apresentaremos nessa escrita uma topografia da Psicologia Jurídica nos territórios acadêmicos, de formação e de atuação. Entendendo que esses territórios possuem fronteiras móveis e relevos acidentados, seria possível compreender em que pontos se aproximam, quais os interesses que estão em jogo e de que forma podemos garantir uma articulação que enfrente o desalinhamento desse debate.

Lembrando da história infantil na qual o "lobo mau" é um dos personagens, é possível pensar que uma das armadilhas desse conto é exatamente a circulação ingênua da menina pelo território desconhecido, a floresta. Nesse sentido, apostamos no mapeamento desses territórios, tanto internos à Psicologia, quanto os territórios do sistema de justiça, como forma de construção de ferramentas críticas e eficazes para enfrentamento dos riscos escondidos nas florestas.

\section{Metodologia - Mapeando territórios de pesquisa, de atuação e de formação}

\author{
Bem no fundo \\ No fundo, no fundo, \\ bem lá no fundo, \\ a gente gostaria \\ de ver nossos problemas \\ resolvidos por decreto \\ a partir desta data, \\ aquela mágoa sem remédio \\ é considerada nula \\ e sobre ela - silêncio perpétuo \\ extinto por lei todo o remorso...
}

(Leminski, 2013, p. 195).

De que maneira a Psicologia se articula com o Direito e como se estabelecem parcerias entre esses dois campos de saber e de fazer? Interesses pactuados entre dois saberes, um que constrói regras, mas se espanta com a subjetividade que escapa ao que está definido por lei e o outro saber que analisa a subjetividade, porém por vezes parece apoiar que o sofrimento seja interrompido por um decreto, assim como no poema de Leminski.

Correndo o risco de produzir também algumas invisibilidades, apresentamos nesse ponto o delinear de territórios diversos pelos quais transitamos e, portanto, refere-se também a uma circulação situada entre a Psicologia Social e a Psicologia Jurídica. Elencamos nesse mapeamento alguns territórios de pesquisa por meio da análise de publicações atuais e certos territórios de atuação, traçando um percurso construindo a reflexão sobre o que está previsto na atuação de profissionais da Psicologia e a própria judicialização que amplia demandas específicas ao judiciário. Aliamos esse debruçar à compreensão do sistema de justiça como não restrito à atuação nos tribunais, e, por último, abordamos os territórios de formação através do debate para reformulação das Diretrizes Curriculares Nacionais (DCN) em 2018 e do levantamento da presença/ausência da disciplina Psicologia Jurídica nas grades curriculares dos cursos de Psicologia da

${ }^{4}$ Para aprofundar esses pontos, é possível consultar Silva (2017), que trabalha com uma análise de casos históricos que tiveram a utilização de ferramentas da Psicologia do Testemunho e Ramos (2015), que analisa experiências de depoimento especial. 
Universidade Federais das capitais ou arredores dos Estados brasileiros e do Distrito Federal ${ }^{5}$.

\section{Territórios de pesquisa}

$\mathrm{Na}$ análise dos territórios de pesquisa, a articulação entre Psicologia e Direito não pode ser considerada uma novidade. Historicamente, a busca de reconhecimento da Psicologia como ciência esteve também articulada à captura desse saber nas instâncias jurídicas (Brito, 2012).

Dentro do território acadêmico, interessa-nos em especial as produções teóricas articuladas com a Psicologia Social. Em manuais de Psicologia Social norte-americana encontramos estudos a partir dessa aproximação com o Direito, por exemplo, pesquisas com júri e sobre os depoimentos das testemunhas (Aronson, Wilson, \& Akert, 2002; Michener, De Lamater, \& Myer, 2005). Contudo, dentre as diversas perspectivas da Psicologia Social, propomos uma interlocução/ interface com o Direito(s) com a Psicologia Social Crítica (Ferreira, 2010) em sua diversidade teórica e epistemológica alinhada com Direitos Humanos, luta antirracista, estudos feministas e um olhar voltado para as instituições seja pela via da esquizoanálise, do movimento institucionalista ou da visão foucaultiana, dentre outras aproximações ${ }^{6}$. Não buscamos um retorno à problematização da área da Psicologia Social sobre " [...] as características, o alcance, os limites e as condições de possibilidade da 'nossa

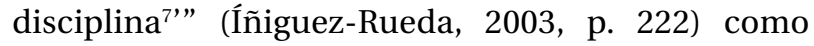
ocorreu no momento da crise do campo. Entendemos a Psicologia Social Crítica, conforme proposto por Îñiguez-Rueda (2003), como:
[...] em permanente estado de problematização, atenta às mudanças que se produzem na esfera das ciências sociais e contribuindo com elas. Mantendo a permeabilidade em relação às ideias e às abordagens de outras disciplinas [...] Mantendo uma severa crítica ao individualismo, um compromisso com os processos de mudanças políticos e sociais (p. 236) ${ }^{8}$.

Desta forma, não propomos a criação de um novo nicho, conforme sinalizado por Christlieb (2019) que tem ocorrido na Psicologia Social, mas buscamos dar visibilidade a algo que já ocorre dentro do território da Psicologia Social de maneira dispersa e avessa ao nome Psicologia Jurídica. A proposta é reunir, é articular e não subdividir. Optamos por salientar a ampliação da discussão da Psicologia Jurídica, incluindo-se a articulação com o(s) direito(s) (Moreira, \& Soares, no prelo ${ }^{9}$ ). Dessa forma, a relação entre os territórios acadêmicos da Psicologia Social e da Psicologia Jurídica encontram-se com fronteiras bastante difusas ou quiçá sem quaisquer demarcações, que termos como direitos, justiça e seus efeitos nas políticas públicas possam ser reconhecidos como pertencentes ao que escolhemos defender como Psicologia Social Jurídica.

Além de publicações específicas de Psicologia Jurídica em livros e artigos, alguns números especiais de revistas importantes mostram a busca dos pesquisadores em articular um campo de debate sobre as práticas judiciárias, o campo dos direitos e da judicialização. Em 2012, a Revista Psicologia \& Sociedade lançou um número especial sobre a temática da Judicialização da vida, tema fruto de

\footnotetext{
${ }^{5} \mathrm{O}$ levantamento curricular foi realizado através de consultas aos materiais disponibilizados nos sites das instituições no primeiro semestre de 2019. A busca referia-se ao nome das disciplinas e, além de Psicologia jurídica, decidimos incluir disciplinas que tenham em seu nome "políticas públicas" e/ ou "direitos humanos". Para essa escrita, analisamos apenas a presença das disciplinas, mas entendemos que, numa análise mais ampliada, seria interessante analisar também os documentos gerais dos cursos, identificando essa discussão em disciplinas com outros nomes.

${ }^{6}$ A autora remete em seu artigo ao trabalho de Hepburn (2003) que reúne no campo denominado como Psicologia Social Crítica, perspectivas como o Socioconstrucionismo, a Psicologia Marxista, a Psicologia Discursiva, o pós-modernismo e o feminismo, dentre outros (Ferreira, 2010).

${ }^{7}$ Tradução livre do original: “[...] las características, el alcance, los límites y las condiciones de posibilidad de 'nuestra disciplina”” (Íñiguez-Rueda, 2003, p. 222).

${ }^{8}$ Tradução livre do original: “[...] en permanente estado de problematización, atenta a los cambios que se producen en la esfera de las ciências sociales y contribuyendo a ellos. Manteniendo la permeabilidad hacia las ideas y planteamientos de otras disciplinas [...]. manteniendo una severa crítica al individualismo, un compromiso con los processos de cambio políticos y sociales [...]” (Î́niguez-Rueda, 2003, p. 236)

${ }^{9}$ Moreira, L. E., \& Soares, L. C. E. C. (no prelo) O que a psicologia social tem a dizer ao campo jurídico? In L. C. E. C Soares, L. E. Moreira, Psicologia social jurídica na trama do(s) direito(s). São Paulo, SP: Cortez.
} 
um encontro internacional de Michel Foucault ocorrido no ano anterior (Nascimento, \& Scheinvar, 2012). No final do ano de 2018, também como desdobramento de um novo encontro ocorrido em 2017, a revista Arquivos Brasileiros de Psicologia lançou um número especial discutindo judicialização (Scheinvar, Aguiar, \& Nascimento, 2018). Também em 2018, com o foco em Sistema Prisional e Segurança Pública, a revista Psicologia: Ciência e Profissão lançou um número especial com 19 artigos, tendo recebido na chamada aberta 69 manuscritos para avaliação (Uziel et al., 2018).

$\mathrm{O}$ crescimento e a manutenção desses debates nos últimos anos, mostra a judicialização como uma importante ferramenta para pensar o presente e seus contornos, caracterizados pelo:

recrudescimento de forças conservadoras a questionar a liberdade de cátedra e materiais de apoio educativo, a forçar passagem para a proliferação de diagnósticos e medicalização, a julgar modos de vida que desviam, a criminalizar movimentos sociais de contestação, a perseguir, condenar e encarcerar corpos pretos, a insistir na colonização do pensamento (Scheinvar et al., 2018, p. 4).

O esforço coletivo de pensar sobre as articulações entre Psicologia e Direito, seja por meio da identificação e da análise de processos de judicialização, seja no desdobramento das práticas punitivas, aponta para a urgência dessa temática no cenário atual. Enquanto campo de pesquisa, apesar da evidência das implicações políticas do avanço da judicialização, as políticas acadêmicas nem sempre respondem imediatamente a esses diagnósticos. Nesse sentido, é importante colocar em questão se essas temáticas já se apresentam abarcadas nos editais e agências de fomento para eventos e pesquisas. O que percebemos é que essas temáticas ainda não se encontram consolidadas ${ }^{10}$, assim como a articulação entre Psicologia e Direito, principalmente quando se refere à Psicologia Social (Moreira, \& Soares, no prelo ${ }^{11}$ ).
Algumas iniciativas de fomento à pesquisa e aos eventos estão presentes no próprio sistema jurídico. Em 2019, foi lançada, pelo Conselho Nacional de Justiça, a quarta edição da série "Justiça Pesquisa” (CNJ, 2019), que busca fomentar pesquisas, realizar análises, diagnósticos do Poder Judiciário e fornecer subsídios técnicos para as políticas judiciárias. Entretanto, chama atenção que, dentre a diversidade de áreas de atuação da justiça, o edital prevê apenas três campos temáticos, dois vinculados ao eixo de Direitos fundamentais - cobertura criminal dos meios de comunicação e vulnerabilidade e exclusão social e um vinculado às políticas públicas do poder judiciário: impactos para a política previdenciária (CNJ, 2019).

Não há como abordarmos as práticas de pesquisa e de escrita sem mencionarmos o lugar da universidade nessa produção, posto que em nosso país esse é o território principal de construção de conhecimento. Então, cabe questionar quem produz pesquisa e escrita em Psicologia Jurídica? Nesse aspecto, torna-se fundamental remeter aos concursos de docentes nessa área. A falta de centralidade dessa informação em âmbito nacional torna desafiador o levantamento de maneira sistematizada. Contudo, podemos citar alguns poucos exemplos de vagas específicas para essa área, tais como: concurso para docente em Psicologia Jurídica na Universidade Federal do Rio de Janeiro em 2008, na Universidade Federal de Campina Grande em 2011 e 2016, e o certame na Universidade Federal de Minas Gerais, em 2015 (vaga alocada no departamento de Psicologia, mas para disciplina obrigatória no Direito).

Diante do exposto, como pensar a produção de pesquisa e de escrita na ausência de docentes da área? O que é possível vislumbrar são questões da Psicologia Jurídica tomadas por pesquisadores/docentes que trabalham em outras áreas, como avaliação psicológica, psicanálise ou Psicologia Social quando apresentam alguma interface mesmo que sutil com o sistema de justiça, mas que não se nomeiam como Psicologia Jurídica.

\footnotetext{
${ }^{10}$ Encontramos alguns grupos de pesquisa de Psicologia Jurídica, mas em alguns espaços acadêmicos a presença ainda é pequena. Não há grupo de trabalho (GT) com essa temática específica na Associação Nacional de Pesquisa e Pós-graduação em Psicologia (ANPEPP) e na Associação Brasileira de Psicologia Social (Abrapso), apesar de muitos trabalhos discutirem direito e justiça, são poucos GT dedicados explicitamente a essa questão.

${ }^{11}$ Moreira, L. E., \& Soares, L. C. E. C. (no prelo) O que a psicologia social tem a dizer ao campo jurídico? In L. C. E. C Soares, L. E. Moreira, Psicologia social jurídica na trama do(s) direito(s). São Paulo, SP: Cortez.
} 
Desenvolver a Psicologia Jurídica no território acadêmico torna-se fundamental para o florescimento de políticas de escrita e de pesquisa nesse campo. De acordo com Brito (2011a) cabe às universidades: "[...] ampliar a reflexão sobre temas em destaque na sociedade, sendo necessário, por vezes, olhar o avesso do objeto, da situação, ou do conceito em pauta" (p. 116). A inexistência de uma formação qualificada específica dos professores e pesquisadores também pode dificultar esse exercício fundamental do ensino de "olhar o avesso" (Brito, 2011a, p. 116), culminando na perpetuação de práticas de colonização da Psicologia pelo Direito. Essa subordinação poderá ocorrer tanto na transmissão do conhecimento, quanto no momento no qual esses psicólogos formados se inserirem no Sistema de Justiça posicionando-se no lugar de subserviência às demandas. Esse debate sobre a inserção laboral acrítica foi sinalizado por Codo (1984), conforme mencionado na introdução, a respeito da área as organizações.

A inclusão de docentes com formação na área nas universidades permite o desenvolvimento de pesquisa, que atualiza e aprofunda as temáticas, ampliando a reflexão sobre as práticas e fundamentando teoricamente a atuação crítica. Observa-se um movimento de redução das atividades desenvolvidas pela Psicologia Jurídica em diversos tribunais e o retorno ao trabalho estritamente pericial (Soares, 2017) e, ainda, práticas absorvidas por bacharéis em direito sob a justificativa de que supostamente atendem à celeridade de justiça na resolução dos conflitos prescindindo de psicólogos, por exemplo, as constelações familiares utilizadas nos fóruns (Marino, \& Macedo, 2018). Assim, partimos para o próximo eixo a ser analisado: a ocupação da Psicologia como lugar de trabalho no território da Justiça.

\section{Territórios de atuação profissional}

Curiosamente, quando se pesquisa as atribuições do psicólogo social de acordo com o Catálogo Brasileiro de Ocupações - CBO (CFP, 1992) encontra-se: “[...] colabora com a Justiça, quando solicitado, apresentando laudos, pareceres e depoimentos, para servir como instrumentos comprobatórios para melhor aplicação da lei e da justiça". A despeito de sua definição marcada pelo aspecto pericial e com um caráter de subordinação às solicitações do judiciário, cabe sinalizar a inclusão dessa interface com a atividade do psicólogo social.
Nesse ensaio sobre o território de práticas da Psicologia, ao consultarmos o mesmo documento supracitado (Brasil, 1992), na definição a respeito do trabalho do psicólogo jurídico depara-se com a seguinte atividade: "Atua no âmbito da Justiça, colaborando no planejamento e execução de políticas de cidadania, direitos humanos e prevenção da violência [...]". Novamente, as fronteiras se movimentam e borram seus limites através das quais é possível construir espaços de trocas.

Pensar a Psicologia Jurídica numa articulação mais ampliada, não apenas com a Psicologia Social, mas também com as políticas públicas e o trabalho em rede, possibilita pensar em campos diversos de atuação que cada vez mais se configuram diretamente com o campo do Direito. Como construir uma Psicologia jurídica preocupada com as políticas públicas e com a promoção de direitos humanos? Estaria sendo considerada a inserção do psicólogo jurídico no campo do Poder Executivo? A resposta é sim, se for mencionado outros espaços já consolidados de entrada da Psicologia Jurídica, tais como a atuação no sistema prisional (Bandeira, 2012; Martins; Beiras, \& Cruz, 2012) ou nas polícias (Nobrega, Siqueira, Turra, Beiras, \& Gomes, 2018) pode-se evidenciar que esse profissional também atua no executivo.

Além desses dois campos mencionados, seria possível citar, por exemplo, as políticas públicas em relação à infância, adolescência, família, na execução da assistência social, no enfrentamento à violência contra a mulher e muitos outros espaços de articulação entre direito(s) e Psicologia. Esses campos, tão importantes para a consolidação de uma abordagem social da Psicologia, nos convocam a análises urgentes diante dos desmontes governamentais instaurados e que colocam em questão direitos tão duramente conquistados.

Compreendendo as fronteiras desse território tão carregado de disputas, importante pensar também que a interface da Psicologia com o direito no campo da execução das políticas públicas nos impulsiona a questionar como essas próprias políticas são construídas. Se estamos assumindo o compromisso na execução de algumas engrenagens estatais, qual é a nossa participação na construção dessas políticas? Ainda percorrendo o catálogo localizamos outro trecho "contribuir para a formulação, revisão e interpretação das leis”. Aqui pode-se compreender que está sendo mencionada uma 
incursão em outro território para além do Judiciário, adentrando no Legislativo.

Esse debate sobre a participação na construção legislativa foi detalhado por Bicalho (2016) que optou por manter esses campos articulados numa Psicologia Jurídica Legislativa, "porque a lei, como prática social, também deve ser tomada por seu processo de construção... lugar para a atuação de uma psicologia que se pretende jurídica" (p. 17-18). Nesse sentido, cabe refletir se somos chamados para executar as políticas elaboradas por outros profissionais ou se também podemos construir esse território.

Uma luta recente nessa área refere-se à polêmica prática do Depoimento especial, instituída pela Lei $\mathrm{n}^{0} 13.431 / 2017$ que foi aprovada sem audiência pública $^{12}$ e que tem impacto direto na atuação dos psicólogos (Arantes, 2016). Entretanto, o debate da atuação da Psicologia no campo legislativo tem se mostrado bem mais amplo do que apenas a discussão na formulação de leis que implicam relação direta ao trabalho dos profissionais da área. Mesmo em temas mais amplos, como por exemplo a Lei do feminicídio, o debate a respeito da criminalização da LGBTfobia ${ }^{13}$, a descriminalização do aborto ${ }^{14}$, dentre outros, é inegável a importância da Psicologia produzir conhecimentos e ferramentas que possibilitem compreender os paradoxos desses debates entre garantias de direitos, a intensificação das normatizações sobre a subjetividade e a defesa pela ampliação das práticas punitivas e pela criminalização.

Desta forma, pode-se trabalhar a construção do campo não como resposta direta às demandas (Amêndola, 2014a) ou às atividades que nos posicionam a executar, mas modificar a própria demanda, a partir da produção de conhecimento (política de pesquisa), da escolha de determinados objetos, de campos-problema. Diante do exposto, o conceito de Sistema de Justiça talvez possa suportar essa articulação entre os três poderes, compreendendo como proposto por Brito (2011b) a distinção entre psicólogxs no judiciário e psicólogxs jurídicos, sendo esses últimos ocupantes de muitos territórios. O cenário de judicialização da vida tem provocado aumento das demandas sociais ao Judiciário que responde criando cargos para psicólogos ou acionando profissionais que já se encontram na rede pública, porém laborando em outras políticas públicas, tais como saúde e assistência social.

Nos territórios de atuação profissional, importante salientar o crescimento de processos éticos contra profissionais no Sistema Conselhos reflete o despreparo para lidar com demandas de elaboração de documentos que são remetidos ao Sistema de Justiça (Amêndola, 2014b). Ampliando a discussão das denúncias, poderíamos pensar que elas emergem relacionadas aos documentos, que dão certa concretude à prática, mas possivelmente traduzem a dificuldade em relação à própria articulação da Psicologia com as instâncias jurídicas, tensionando a serviço de quem está a Psicologia e quais os riscos e benefícios da nossa prática. Nesse sentido, a atuação está diretamente relacionada com a formação na Psicologia, como apresentaremos no próximo território.

\section{Territórios de formação}

O mapeamento dos territórios de pesquisa e atuação profissional nos convocam a pensar na amplitude desse debate para a Psicologia. Entretanto, como docentes na área, quando pensamos os territórios de formação, percebemos um descompasso que produz uma invisibilidade desses debates nos cursos de Psicologia. Que psicologias ocupam os territórios de formação? Quem formamos? O ensino de Psicologia Jurídica na graduação em Psicologia não é obrigatório e geralmente compõe a grade curricular na condição de disciplina eletiva.

Diante do exposto, como estratégia metodológica mapeamos territórios de formação buscando

\footnotetext{
${ }^{12}$ Ainda no momento de tramitação como projeto de lei (PL no 3.792/2015) no legislativo, Arantes (2016) chamou atenção para a ausência de amplo debate com: "representantes de Políticas Públicas nas áreas de Saúde, Assistência e Educação, bem como representantes dos Conselhos Profissionais de categorias envolvidas nas atividades previstas pelo PL, como é o caso de psicólogos e assistentes sociais - profissionais estes que geralmente compõem as equipes técnicas dos diversos serviços da chamada Rede de Proteção, e também, a ausência de representantes do próprio Conselho Nacional dos Direitos da Criança e do Adolescente (CONANDA)” (Arantes, 2016).

${ }^{13}$ Inegável a importância das Resoluções do Conselho Federal de Psicologia sobre sexualidade (CFP Resolução nº 01/1999 e nº 01/2018), que além de orientar a atuação dos profissionais, também tem servido para o amplo debate social.
}

${ }^{14}$ Tramita, desde 2017, no Supremo Tribunal Federal uma Arguição de Descumprimento de Preceito Fundamental (ADPF 442) que questiona a política proibicionaista do aborto. Em agosto de 2018 aconteceu audiência pública com a participação da Psicologia, por meio do Sistema Conselhos. 
nas grades dos cursos - ofertados pelas Universidades Federais localizadas nas capitas brasileiras e no distrito federal - as disciplinas Psicologia jurídica; Políticas públicas e Direitos humanos. Optamos pela escolha das universidades federais em decorrência de sua representatividade no território acadêmico e pela autonomia universitária presente na elaboração das matrizes curriculares. Nesse sentido, remetemos ao trabalho desenvolvido por Macedo, Lima, Dantas e Dimenstein (2017) que denotam a transnacionalização das grades de algumas faculdades particulares compradas por grandes grupos educacionais que padronizam o que será ofertado independentemente das especificidades regionais e nacionais:

[...] há a necessidade de superar determinadas formas de atuação hegemônicas e que estão "massificadas" na profissão. E por isso são reforçadoras de tecnicismos e que têm como base uma formação descontextualizada, cujo modelo hegemônico desconsidera as realidades locais, as características da população, as necessidades de saúde e assistência social, as atividades produtivas, as relações políticas e vulnerabilidades psicossociais em diferentes contextos (Macedo, Lima, Dantas e Dimenstein, 2017, p. 865).

No levantamento realizado constatou-se que dentre as $\mathbf{2 6}$ universidades federais ${ }^{15}$, localizadas nas capitais ou arredores ${ }^{16}$, que possuem curso de Psicologia, apenas quatro ofertavam a disciplina de Psicologia Jurídica como obrigatória e uma possuía matéria com proposta semelhante intitulada "Psicologia, Justiça e Direitos Humanos". Em outras onze aparece, em suas grades curriculares, como optativa, complementar, eletiva ou núcleo livre ${ }^{17}$, dependendo das denominações adotadas por cada projeto político pedagógico. Em uma universidade, seria a 12a, a matéria optativa constava sob o título "Psicologia e Formas Jurídicas".
A respeito das disciplinas que poderiam ter conteúdos afins, buscou-se pelos descritores direitos humanos e políticas públicas. No campo dos direitos humanos localizou-se duas universidades com oferta de obrigatórias com os nomes "Ética e direitos humanos" e "Políticas Públicas, Direitos Humanos e Práticas Psicossociais" (essa última reúne os dois termos, sendo contabilizada duas vezes). Outros cinco cursos que disponibilizavam como optativas. Os resultados da busca pelo segundo descritor foi o que trouxe maior diversidade no que tange aos títulos.

Com o título de "Psicologia e Políticas públicas" ou "Fundamentos em Políticas Públicas", oito cursos disponibilizavam como obrigatórias, um deles além dessa disciplina ofertava também como obrigatórias "Psicologia e Políticas Públicas em Educação" e "Psicologia e Políticas Públicas em Saúde". Outra universidade não oferecia disciplina mais geral, porém ofertava como obrigatórias as duas matérias sobre saúde e educação com os mesmos nomes citados anteriormente. Diferentemente do que ocorreu com os demais descritores, nos quais a maioria da oferta era optativa, apenas três cursos ofertavam essa disciplina mais geral como optativa. Contudo, cabe destacar que em cinco universidades, existiam disciplinas optativas de políticas públicas especificadas por área, sem a oferta da obrigatória, como saúde (saúde mental e saúde coletiva também apareceram), assistência social, trabalho ou educação. A maior inserção de matérias a respeito de políticas públicas reflete e responde à mudança no campo de atuação dos psicólogos, que encontram espaços de trabalho nas diversas políticas, sendo considerado inclusive quando encontramos disciplinas específicas de cada área (saúde, educação ou assistência social) denotando a ampliação de carga horária para permitir aprofundar o conhecimento.

Diante do exposto, o que é possível decantar é a reduzida oferta de disciplinas na área de Psicologia Jurídica e de direitos humanos ${ }^{18}$. A presença de deba-

\footnotetext{
${ }^{15} \mathrm{Na}$ Universidade Federal do Amapá (Unifap) não há graduação em Psicologia.

${ }^{16} \mathrm{Na}$ UFSE não tem curso de Psicologia em Aracajú, apenas em São Cristovão que fica na região metropolitana, cerca de 23 km. Na UFT não há oferta de graduação em Psicologia em Palmas, mas em Miracema que fica 90 km de distância. Por fim, na UFPI, o curso de Psicologia não é disponibilizado na capital Teresina, mas em Parnaíba que não se caracteriza como região metropolitana, pois fica distante $340 \mathrm{~km}$. No entanto, em função da importância de representatividade dos Estados, decidimos pela inclusão das três na análise. Como a Unifesp possui curso de Psicologia apenas na baixada santista e diante da relevância e visibilidade da USP, optamos por considerar apenas a USP como representante do estado de São Paulo no levantamento.
}

${ }^{17}$ Para facilitar a compreensão optamos pelo termo optativa, mesmo quando a universidade adotou outra terminologia. 
tes sobre políticas públicas, certamente, inclui discussões sobre a garantia dos direitos, mas não necessariamente irá se aproximar da reflexão a respeito da relação com a Justiça.

Em 2018, houve mobilização para revisão das DCN para os cursos de graduação em Psicologia, coordenada pelo Conselho Federal de Psicologia (CFP), pela Associação Brasileira de Ensino de Psicologia (ABEP) e pela Federação Nacional dos Psicólogos (FENAPSI). Aproveitando esses ecos sobre a discussão da formação de psicólogo no Brasil, buscamos questionar se, diante das transformações no campo da Psicologia, em especial a ampliação da judicialização das vidas, não seria necessário posicionar as discussões da articulação entre Psicologia e Direito como eixo obrigatório da formação sob uma perspectiva crítica da Psicologia Social. O extenso trabalho desenvolvido ao longo de 2018 está descrito no relatório já publicado (CFP, 2018) e estava relacionado com a revisão proposta aos cursos de Graduação da área da Saúde.

A submissão das DCN exclusivamente à área da saúde é um dos pontos de dissenso e teve posição contrária expressada pela Associação Nacional de Pesquisa e Pós-graduação em Psicologia: "A Psicologia é diversa e plural, inserida em distintas políticas públicas, como as de educação, trabalho e assistência social, além da saúde" (ANPEPP, 2018). Em nota publicada ainda em 2018, apesar de reconhecer o trabalho empreendido, a ANPEPP chama atenção para a ausência de outras entidades de formação e o calendário relativamente curto, além da concentração na área da saúde que não condiz com a classificação da Psicologia em instâncias como Conselho Nacional de Desenvolvimento Científico e Tecnológico - CNPq e Coordenação de Aperfeiçoamento de Pessoal de Nível Superior - Capes (ANPEPP, 2018). Em que pese não ter menção direta à articulação com o direito, a nota aponta para o reconhecimento de campos diversos de atuação e que, portanto, precisariam também estar contemplados na formação.

É possível que essa revisão das DCN contemple novos ciclos de debate e ainda sofra alterações, mas já nos possibilita compreender os territórios de formação e a presença ou não do debate da Psicologia Jurídica até o momento ${ }^{19}$. Mesmo que existam reformulações, a minuta produzida em 2018 fornece pistas sobre os parâmetros debatidos para a formação, num momento "de retração das políticas de direito e acessibilidade, de rupturas nas políticas públicas nos campos da saúde, educação, seguridade social, de precarização dos processos de trabalho, de redução de recursos à ciência e à tecnologia do país" (CFP, 2018, p. 36), como o próprio relatório observa, assumindo o compromisso com "um projeto de formação para a Psicologia que contemple a pluralidade, a competência acadêmica e o compromisso com o aperfeiçoamento da sociedade, pautada numa perspectiva de direitos cidadãos plenos" (CFP, 2018, p. 36).

Na minuta que temos acesso até o momento, a meta central da graduação em Psicologia seria a formação de profissionais que atuem em "defesa da cidadania, da dignidade humana, da saúde integral e tendo como transversalidade, em sua prática, a determinação social dos fenômenos e processos humanos" (CFP, 2018, art. 3, p. 114). Complementando, o artigo $4^{\circ}$ determina a importância da graduação "assegurar uma formação científica, ética, política, generalista, humanista, crítica, reflexiva, democrática e laica, embasada nos Direitos Humanos" (CFP, 2018, p. 114).

Esses dois pontos gerais são interessantes, pois de maneira ampla dialogam com os debates da Psicologia Jurídica e com princípios que os territórios de pesquisa e de atuação profissional também apontam como requisitos necessários à articulação da Psicologia com o Direito. Entretanto, analisamos também as referências diretas às áreas da Psicologia e, nesses pontos, a minuta parece não sustentar uma vinculação específica com a Psicologia Jurídica.

$\mathrm{Na}$ descrição dos eixos estruturantes, o documento aponta as políticas públicas, citando especificamente: "conhecimentos nas áreas de Assistência Social, Educação, Saúde, Trabalho, Segurança Pública, Proteção e Defesa Civil, entre outras" (CFP, 2018, p. 116). Não fica claro porque essas áreas são citadas

\footnotetext{
${ }^{18}$ Outros levantamentos de espaços formativos poderiam ser considerados em pesquisas futuras, tais como a presença de laboratórios ou núcleos de pesquisa, de projetos de extensão ou de oferta de estágios internos ou externos à universidade contabilizados para a conclusão do curso. Da mesma forma, as diferenças regionais poderiam ser pistas interessantes sobre as diferenças de formação, mas essa questão escapa da proposta do presente artigo e, portanto, não abordaremos essa temática aqui.
}

${ }^{19}$ Esses trâmites estão sendo analisados e definidos no âmbito do Fórum de Entidades Nacionais da Psicologia Brasileira (FENPB). 
e não outras, mas certamente são escolhas que produzem efeitos. A Psicologia Jurídica pensada aqui de forma mais ampla encontra espaços em alguns campos mencionados, tais como segurança pública e assistência social, porém questiona-se a invisibilidade da palavra "justiça" como área de ocupação da Psicologia. Nas aptidões esperadas dos egressos, salientamos três pontos:

$\mathrm{XV}$ - elaborar registros documentais decorrentes da prestação de serviços psicológicos, tais como pareceres técnicos, laudos, relatórios e evolução em prontuários, de acordo com os preceitos éticos e legais;

XVI - valorizar e contribuir para a elaboração, implementação, acompanhamento e avaliação de políticas públicas relacionadas à atuação profissional do psicólogo e promotoras de direitos e cidadania;

XVII - atuar nas políticas públicas, de forma interdisciplinar, multi profissional, interprofissional e intersetorial, contemplando as referências teórico-metodológicas do campo da Psicologia, as diretrizes das políticas públicas, as especificidades sócio-territoriais e os processos de cidadania, participação e controle social, comprometendo-se com a produção de conhecimento (CFP, 2018, p. 119, grifos nossos).

De maneira geral, podemos compreender que alguns pontos comumente articulados à Psicologia Jurídica estão aqui contemplados, desde o fazer mais restrito à produção de documentos até aptidões voltadas à abordagem crítica e ampliada. Entretanto, é possível ainda manter o questionamento a respeito da dispersão dessa área e o não enfrentamento de sua existência nos territórios de formação.

Articulando as fronteiras entre os territórios de formação, os territórios de atuação profissional e os territórios de pesquisa, mesmo com o reconhecimento da possibilidade de que esses debates e habilidades apareçam empreendidos de maneira pulverizada em outras disciplinas, ainda assim, os territórios de formação permanecem invisibilizando esse debate, em especial, quando pensamos na ampliação de demandas jurídicas ao campo da Psicologia.

Ao refletir sobre a Psicologia em articulação com o Direito, cabe destacar o descompasso entre a obrigatoriedade da oferta de conteúdos de Psicologia Jurídica no bacharelado em Direito (Resolução CNE/CES No 9, 2004) e a tímida inclusão na graduação em Psicologia. A inexistência na formação da graduação em Psicologia parece remeter a um território desocupado, sem função social e que, portanto, pode ser ocupado, por exemplo, pelo direito e não pela Psicologia, como observamos quando a disciplina de Psicologia Jurídica nos cursos de direito, por vezes, é lecionada por bacharéis em direito e não por psicólogos.

Importante marcar novamente que estamos falando da formação levando em consideração não apenas as legislações que preveem a avaliação técnica da Psicologia por incidirem sobre questões subjetivas, mas também outras questões que compõem esse cenário de judicialização. Na contramão dessa argumentação, poderíamos pensar nos benefícios de um debate dentro de outras disciplinas que, obviamente, é uma importante articulação. Contudo, o caráter opcional e disperso pode fragilizar a formação nesse campo.

Entretanto, diante desse mapeamento dos territórios da Psicologia, consideramos necessária a garantia do debate de questões que se fazem visíveis através da Psicologia Jurídica, tendo em vista que alguns conceitos centrais nesse campo são também constitutivos da subjetividade no presente. O que se propõe é o destaque para a relevância reflexiva e contextualizada sócio-histórico e politicamente dos conteúdos a serem inseridos em tais matérias e seus desdobramentos em termos de espaços para pesquisa, estágio e extensão, a partir da inclusão nas Universidades de docentes voltados para a Psicologia Social Jurídica. Como nos alerta Amêndola (2014A), o papel da Universidade não pode ser voltado "[...] a formar competências operacionais para atender às demandas do mercado, criando, em contrapartida, incompetentes para o exercício da reflexão crítica e da liberdade, portanto, para o exercício da ética" (p. 978). Aguiar et al. (2018) sinalizam para os efeitos desse posicionamento na prática profissional:

Nos processos de formação de trabalhadores sociais temos que nos haver com o direito e o humano como conceitos/figuras que, naturalizadas, são evocadas como universais. A naturalização é a operação que esvazia a dimensão sociopolítica das práticas, fazendo morrer a história, 
as condições de emergência, que envolvem desejos, interesses e necessidades em disputa, favorecendo a manutenção de versões pretensamente neutras e justas das práticas (p. 86).

De maneira complementar, Brito (2011a) retrata o processo de aprendizagem "[...] não como uma trilha que depois de certo tempo se chega ao final, mas como um caminho que se percorre [...]" (p. 125). Nesse sentido, a presença da matéria nas grades curriculares possibilitará a entrada de docentes que poderão percorrer a floresta auxiliando aos discentes e, quiçá futuros profissionais dessa área, a observarem as flores, as árvores, as luzes, as sombras e talvez, até mesmo, o lobo mau.

\section{Considerações finais}

A fim de compreender o descompasso na ocupação da Psicologia Jurídica em territórios de pesquisa, de atuação e de formação, a partir da dúvida se seria a Psicologia Jurídica o novo "lobo mau" da Psicologia, enfrentamos a tarefa de mapear esses territórios. Aproveitando ainda essa metáfora, em aproximação com a história de chapeuzinho vermelho e o lobo mau, ousamos enfrentar a floresta, não em posição ingênua, mas buscando construir ferramentas de ocupação desses espaços, conhecendo seus riscos e inventando práticas comprometidas com os princípios da Psicologia.

Então, seria a Psicologia jurídica o novo lobo mau da Psicologia? Diante do receio da Psicologia Social quando nomeamos a prática e a produção do conhecimento nessa perspectiva crítica como Psicologia Jurídica, por vezes, reforça-se esse lugar de vilão. Para além da definição de uma identidade específica, Psicologia Social Jurídica, interessa dar visibilidade a essa vasta área da Psicologia Social, de permitir que ela encontre olhares críticos e reflexivos que sempre se direcionaram para essa interface, mas que rejeitavam essa associação, para que se torne possível desconstruir as invisibilidades produzidas no território acadêmico, nas políticas de escrita e de pesquisa quando busca-se essa aproximação teórica. Essa convocação para o diálogo, para a aproximação dos psicólogos sociais, é a proposta dessa produção e, por esse caminho foi tecida por pesquisadoras/docentes da Psicologia Jurídica construída sob essa perspectiva.
Desta forma, o objetivo do presente artigo foi problematizar as ausências e as ocupações da Psicologia Jurídica nos territórios acadêmicos e de pesquisa, territórios de atuação profissional e territórios de formação. Perpetuar as (in)visibilidades pode abrir espaço para uma preocupação instrumental com o fazer dx psicólogx jurídicx, a partir do que é endereçado pelo Direito de forma acrítica, assim como deve-se refletir sobre os riscos desta forma de atuação para a construção da Psicologia como ciência e profissão.

Para posicionarmos um profissional cuja atuação nessa interface permitirá o questionamento do que é solicitado nesses territórios da Justiça é necessário romper com a cisão entre teoria e prática. A produção do conhecimento e aprofundamento teórico encontra espaço nas universidades, denotando a importância da oferta da disciplina e da inserção de docentes dessa área para possibilitar a inclusão desse debate nas políticas científicas de fomento à pesquisa e de divulgação científica. Desta forma, a articulação entre a produção de conhecimento e a atividade profissional teria como alicerce a reflexão crítica e não o utilitarismo da prática.

Diante do cenário de desmontes dos últimos anos, assim como a relevância e centralidade dada ao judiciário no próprio contexto político brasileiro, essa reflexão busca pensar os riscos de não pautarmos de maneira ampliada a articulação da Psicologia crítica com o campo do Direito. Como algumas críticas feitas à judicialização da vida que referem esse processo como uma forma de colonização da subjetivação, numa lógica de resistência, propomos a ocupação inversa. Não para congestionar o judiciário de novas demandas, pelo contrário, mas para garantir também a atuação crítica desde muito perto dessa interface.

Se a Psicologia Social não se implicar também com as instâncias jurídicas, acabamos por poupar os operadores do direito do tensionamento que o referencial crítico possibilita. Uma lógica de ocupação do território jurídico. Em tempos de acirramento de disputas políticas, de intensificação de discursos de ódio, é estratégico e imperioso que possamos adentrar e permanecer nesse espaço que produz práticas muito díspares nas quais, paradoxalmente, coexistem ideais de garantia de direitos e também práticas que produzem a manutenção de desigualdades. 


\section{Referências}

Aguiar, K.; Fonseca, V.; Daros, R. (2018). Linhas, riscos e rabiscos: Considerações sobre o presente. Arquivos Brasileiros de Psicologia, 70(spe), 75-91.

Amêndola, M. F. (2014b). A prática psicológica de avaliação pelo olhar dos discursos contidos nos processos disciplinares éticos. In L.S.M Ayres, C.S. Barbosa, \& F. M. L. Ribeiro (Org.), Ética e psicologia:Reflexões do Conselho Regional de Psicologia do Rio de Janeiro (pp. 75-100). Rio de Janeiro, RJ: Conselho Regional de Psicologia do Rio de Janeiro.

Amêndola, M. F. (2014a). Formação em psicologia, demandas sociais contemporâneas e ética: Uma perspectiva. Psicologia: Ciência e Profissão, 34(4), 971-983. https://doi.org/10.1590/1982-370001762013

Arantes, E. M. M. (2008). Mediante quais práticas a psicologia e o direito pretendem discutir a relação? Anotações sobre o mal-estar. In C. Coimbra, L. Ayres, \& M. L. Nascimento (Orgs.), Pivetes: Encontro entre a psicologia e o judiciário (pp. 131-148). Curitiba: Juruá.

Arantes, E. M. M. (2016, 12 agosto). É suficiente recorrer à Convenção da ONU sobre os Direitos da Criança em detrimento da legislação nacional? Notas a propósito do Projeto de Lei No 3792, de 2015. Empório do Direito, 12/08/2016. Recuperado de https://emporiododireito.com.br/leitura/e-suficiente-recorrer-a-convencao-da-onu-sobre-os-direitos-da-crianca-em-detrimento-da-legislacao-nacional-notas-a-proposito-do-projeto-de-lei-n-3792-de-2015

Aronson, E., Wilson, T. D., \& Akert, R. M. (2002). Psicologia social. Rio de Janeiro, RJ: LTC.

Associação Nacional de Pesquisa e Pós-graduação em Psicologia - ANPEPP. (2018). Nota da Associação Nacional de Pesquisa e Pós-Graduação em Psicologia sobre a Proposta de Reformulação das Atuais Diretrizes Nacionais Curriculares da Psicologia. DCNS e o contexto atual: Por um amplo debate com todas as entidades da Psicologia. Disponível em: http://www.anpepp.org.br/download/download?ID_DOWNLOAD=201

Bandeira, M. M. B. (2012). Sistema prisional contando e recontando histórias: As oficinas de leitura como processos inventivos de intervenção. Curitiba: Juruá.

Bicalho, P. P. G. (2016) Da execução à construção das leis: A psicologia jurídica no legislativo brasileiro. In E. P. Brandão, Atualidades em psicologia jurídica (pp. 17-34). Rio de Janeiro, RJ: Nau.

Brasil (1992). Ministério do Trabalho. Classificação brasileira de ocupações (CBO). Brasília, DF: o autor.

Brito, L. M. T. (2012). Anotações sobre a psicologia jurídica. Psicologia Ciência e Profissã,. 32(no. spe), 194-205. https://doi.org/10.1590/S1414-98932012000500014

Brito, L. M. T. (2011b). Avaliação psicológica no contexto das instituições de justiça. In Conselho Federal de Psicologia - CFP. (Org.). Ano da avaliação psicológica: Textos geradores (pp. 85-88). Brasília:, DF: o autor.

Brito, L. M. T. (2011a). O papel da Universidade na formação de profissionais competentes para lidar com casos de violência sexual. In: M. R. F. Azambuja, \& M. H. M. Ferreira. (Org.). Violência sexual contra crianças e adolescentes (pp. 116-126). Porto Alegre, RS: Artmed.

Brito, L. M. T. (1993). Se-pa-ran-do: Um estudo sobre a atuação do psicólogo nas Varas de Família. Rio de Janeiro, RJ: Relume-Dumará.

Christlieb, P. F. (2019). Todos los psicólogos sociales: Recapitulación de cuatro o cinco décadas. Athenea Digital, 19(1), 1-25. https://doi.org/10.5565/rev/athenea.2444

Codo, W. (1984) O papel do psicólogo na organização industrial (notas sobre o lobo mau em Psicologia). In W. Codo, Psicologia social: O homem em movimento (pp. 195-202). São Paulo, SP: Brasiliense.

Codo, W. (1996, setembro/outubro). Entrevista: Precisamos de trabalho, não de força de trabalho. Jornal do CRP/ $S P, 16(101)$.

Conselho Federal de Psicologia - CFP. (2018). Ano da formação em psicologia: Revisão das diretrizes curriculares nacionais para os cursos de graduação em psicologia .São Paulo, SP: o autor.

Conselho Federal de Psicologia - CFP. (1992). Atribuições profissionais do psicólogo no Brasil: Contribuição do Conselho Federal de Psicologia ao Ministério do Trabalho para integrar o catálogo brasileiro de ocupações. Brasília, DF: o autor. Recuperado de http://site.cfp.org.br/wp-content/uploads/2008/08/atr_prof_psicologo.pdf 
Conselho Nacional de Justiça - CNJ. (2019). Edital de convocação pública: 4 a edição da Séria "Justiça Pesquisa". Recuperado de http://www.cnj.jus.br/files/conteudo/arquivo/2019/03/03f4982ff120adbefc05b05e 17906e41.pdf

Ferreira, M. C. (2010). A psicologia social contemporânea: Principais tendências e perspectivas nacionais e internacionais. Psicologia: Teoria e Pesquisa, 26(n. spe), 51-64. https://doi.org/10.1590/S0102-37722010000500005

Foucault, M. (2006). A vida dos homens infames. In: M. Foucault, Estratégia, poder-saber. Ditos e escritos: IV (2a ed., pp. 203-222; V. L. A. Ribeiro, trad.). Rio de Janeiro, RJ: Forense Universitária.

Íñiguez-Rueda, L. (2003). La psicología social como crítica: Continuismo, estabilidad y efervescencias; Tres décadas después de la crisis. Revista Interamericana de Psicología, 37(2), 221-238.

Lei No 13.431, de 4 de abril de 2017. Estabelece o sistema de garantia de direitos da criança e do adolescente vítima ou testemunha de violência e altera a Lei no 8.069, de 13 de julho de 1990 (Estatuto da Criança e do Adolescente). Diário Oficial da União, 5 de abril de 2017.

Leminski, P. (2013). Toda poesia. São Paulo, SP: Companhia das Letras.

Lemos, F. C. S. (2018). O governo da subjetividade por meio da judicialização no dispositivo de segurança. Arquivos Brasileiros de Psicologia, 70(spe), 142-151.

Lima, F. (2018). Bio-necropolítica: diálogos entre Michel Foucault e Achille Mbembe. Arquivos Brasileiros de Psicologia, 70 (spe), 20-33.

Macedo, J. P., Lima, M. S. S., Dantas, C., \& Dimenstein, M. (2017). Transnacionalização do Ensino Superior: Impactos nos processos formativos em Psicologia no Brasil. Psicologia: Ciência e Profissão, 37(4), 852-868. https://dx.doi.org/10.1590/1982-3703004272016

Marino, S., \& Macedo, R. M. S (2018). A constelação familiar é sistêmica? Nova Perspectiva Sistêmica, (62), 24-33.

Martins, S., Beiras, A., \& Cruz, R. M. (Org.) (2012). Reflexões e experiências em psicologia jurídica no contexto criminal/penal. São Paulo, SP: Vetor.

Michener, H., DeLamater, J. D., \& Myer, D. J. (2005). Psicologia social. São Paulo, SP: Pioneira Thomson Learning

Nascimento, M. L., \& Scheinvar, E. (2012). Editorial. Psicologia \& Sociedade, 24(spe), 01. https://doi.org/10.1590/ S0102-71822012000400001

Nobrega, L. M. A., Siqueira, A. C., Turra, E. T., Beiras, A., \& Gomes, M. M. (2018). Caracterizando a psicologia policial enquanto uma psicologia social jurídica. Arquivos Brasileiros de Psicologia, 70(3). 148-165.

Ramos, S. I. S. (2015) Depoimento especial de crianças: Multiversos em cena (Tese de doutorado). Instituto de Psicologia, Universidade Federal do Rio de Janeiro, Rio de Janeiro, RJ, Brasil.

Resolução CFP No 1/1999, de 22 de março de 1999. Estabelece normas de atuaçãopara os psicólogos em relação à questão da orientação sexual. Brasília, DF: Conselho Federal de Psicologia.

Resolução CFP No 1/2018, de 29 de janeiro de 2018. Normas de atuação para as psicólogas e os psicólogos em relação àspessoas transexuais e travestis. Brasília, DF: Conselho Federal de Psicologia.

Resolução CNE/CES Nº 9, de 29 de setembro de 2004. Institui as Diretrizes Curriculares Nacionais do Curso de Graduação em Direito e dá outras providências. Diário Oficial da União, 1 de outubro de 2004.

Scheinvar, E., Aguiar, K., \& Nascimento, M. L. (2018). A judicialização da vida - ensaios sobre transgressões. Arquivos Brasileiros de Psicologia, 70(spe), 3-5.

Silva, J. F. (2017). Prometo dizer da verdade: A psicologia do testemunho na história da criminologia brasileira. Curitiba: CRV.

Soares, L. C. E. C. (2017). Para além da perícia: As (im)permanências dos psicólogos nas varas de família. In: M. Therense, C. F. B. Oliveira, A. L. M. Neves, \& M. C. H. Levi, Psicologia jurídica e direito de família: Para além da perícia psicológica (pp. 142-168). Manaus, AM: UEA Edições.

Uziel, A. P., Scisleski, A. C. C., Barros, J. P. P., \& Bicalho, P. P. G. (2018). Sistema prisional e segurança pública: Inquietações e contribuições da/à psicologia. Psicologia: Ciência e Profissão, 38(spe2), 3-9. https:/ / doi.org/10.1590/19823703000122018 


\section{Lisandra Espíndula Moreira}

Docente Adjunta da Universidade Federal de Minas Gerais. Belo Horizonte - MG, Brasil.

E-mail: lisandra.ufmg@gmail.com

(iD) https://orcid.org/0000-0001-9356-3416

\section{Laura Cristina Eiras Coelho Soares}

Docente Adjunta da Universidade Federal de Minas Gerais. Belo Horizonte - MG, Brasil.

E-mail: laurasoarespsi@yahoo.com.br

(iD) https://orcid.org/0000-0003-0859-7625

Endereço para envio de correspondência:

Av. Antônio Carlos, 6.627, Departamento de Psicologia/FAFICH. Campus Pampulha. CEP 31.270-901.

Belo Horizonte, MG

Recebido:24/06/2019

Aceito: 22/07/2019

Received:06/24/2019

Approved: 07/22/2019

Recibido:24/06/2019

Aceptado: 22/07/2019

Como citar: Moreira, L. E., \& Soares, L. C. E. C. (2019). Psicologia jurídica: Notas sobre um novo lobo mau da Psicologia. Psicologia: Ciência e Profissão, 39(n.spe 2), 125-140. https://doi.org/10.1590/1982-3703003225555

How to cite: Moreira, L. E., \& Soares, L. C. E. C. (2019). Juridical Psychology: Notes on a new big bad wolf stereotype. Psicologia: Ciência e Profissão, 39(n.spe 2), 125-140. https://doi.org/10.1590/1982-3703003225555

Cómo citar: Moreira, L. E., \& Soares, L. C. E. C. (2019). Psicología jurídica: Notas sobre el nuevo lobo malo de la Psicología. Psicologia: Ciência e Profissão, 39(n.spe 2), 125-140. https://doi.org/10.1590/1982-3703003225555 